\title{
Medicine packaging pictograms in the context of the electronic product information (ePI) proposal
}

\author{
Violeta Getova (D) , ${ }^{1,2}$ Ilko Getov (D) ${ }^{3}$
}

Contemporary drug regulations and pharmacovigilance have to search constantly for innovative ways to improve the quality of drug safety information offered to the public, patients and medical specialists. The problem of reliability of information is well known in healthcare, and has become especially current in the age of the internet and COVID-19. ${ }^{1}$ During the last decade, many approaches have been adopted in order to assist both patients and healthcare specialists in matters regarding medicinal products. One recent example is the development of the Medical Terms Simplifier introduced by the European Medcines Agency (EMA) following the inclusion of patients in the spontaneous reporting of adverse drug reactions in 2012 and the introduction of ad hoc public hearings during referrals of drug safety in 2017. It is a compilation of terms to be used in delivery of user-friendly drug information. ${ }^{2}$ All this points to greater patient involvement in treatment decisions.

To benefit from these tools, patient awareness and compliance with treatment is key. A study conducted in Bulgaria showed that those using medicine on a daily basis were less informed on adverse drug reactions than respondents who used medicines only occasionally. In addition, participants in this survey did not recognise the patient leaflet as a source of drug information. ${ }^{3}$ This indicates a rather significant gap in the overall health education and could potentially lead to irrational, ineffective and even dangerous medicine use. In the context of all the activities which the EMA undertakes towards patient inclusion, an appropriate future goal is the improvement of society's health education. It is extremely important

\footnotetext{
'Pharmacovigilance and Clinical Trials, Bulgarian Drug Agency, Sofia, Bulgaria

${ }^{2}$ Natural sciences, New Bulgarian University, Sofia, Bulgaria

${ }^{3}$ Social Pharmacy, Faculty of Pharmacy, Medical University Sofia, Sofia, Bulgaria
}

Correspondence to Dr Violeta Getova, Pharmacovigilance and Clinical Trials, Bulgarian Drug Agency, Sofia, Bulgaria; violeta.getova@gmail.com for public health that a clear distinction is made between scientific-based information and fake news.

Probably one of the most important gaps in social order shown by the COVID-19 pandemic is the need for an update in several areas including healthcare and dissemination of reliable information. As

\begin{tabular}{|c|c|c|}
\hline Country & Text on the legal status & Symbol \\
\hline Bulgaria & $\begin{array}{l}\text { Prescription only } \\
\text { Special prescription (narcotics) } \\
\text { Limited prescription (for hospital use only) } \\
\text { For hospital use } \\
\text { OTC }\end{array}$ & Two red/blue stripes \\
\hline France & $\begin{array}{l}\text { Prescription only } \\
\text { Special prescription +additional considerations } \\
\text { For hospital use } \\
\text { On hospital prescription } \\
\text { Initial hospital prescription } \\
\text { Prescription by a specialist } \\
\text { Use by specialist } \\
\text { Urgent use }\end{array}$ & $\begin{array}{l}\text { Red or green rectangle in which the } \\
\text { warning text is placed }\end{array}$ \\
\hline Hungary & $\begin{array}{l}\text { Prescription only } \\
\text { OTC } \\
\text { Prescription only for ambulatory use } \\
\text { Prescription only for ambulatory use under supervision of a specialist } \\
\text { Special prescription for hospital use } \\
\text { On special prescription, narcotic/psychotropic content } \\
\text { On special prescription, could lead to misuse or abuse } \\
\text { On special prescription, new medicine with not enough known about } \\
\text { ADR }\end{array}$ & N/A \\
\hline Germany & $\begin{array}{l}\text { Prescription only } \\
\text { OTC, only in pharmacy } \\
\text { For hospital use }\end{array}$ & $\mathrm{N} / \mathrm{A}$ \\
\hline Italy & $\begin{array}{l}\text { OTC } \\
\text { OTC for self-treatment } \\
\text { Prescription only } \\
\text { Prescription only for unique dispensing } \\
\text { On special prescription } \\
\text { On special prescription for unique dispensing for a certain patient } \\
\text { On special prescription, narcotic/psychotropic content } \\
\text { For hospital use } \\
\text { Use by specialist }\end{array}$ & N/A \\
\hline Poland & $\begin{array}{l}\text { OTC } \\
\text { Prescription only } \\
\text { On limited prescription } \\
\text { On special prescription } \\
\text { For hospital use }\end{array}$ & $\begin{array}{l}\text { OTC } \\
\text { Rp and Rpz } \\
\text { Rpw } \\
\text { Lz }\end{array}$ \\
\hline Slovenia & $\begin{array}{l}\text { For hospital treatment } \\
\text { For health institution treatment } \\
\text { For diagnosis in hospital and ambulatory treatment } \\
\text { For ambulatory treatment } \\
\text { OTC, available in pharmacy only } \\
\text { OTC }\end{array}$ & $\begin{array}{l}\text { H } \\
\text { ZZ } \\
\text { H/Rp } \\
\text { Rp/Spec }\end{array}$ \\
\hline Spain & $\begin{array}{l}\text { Prescription only } \\
\text { For hospital use } \\
\text { For diagnosis in hospital } \\
\text { Prescription only for ambulatory use under supervision of a specialist } \\
\text { Hospital package } \\
\text { Long-term treatment }\end{array}$ & $\begin{array}{l}\mathrm{H} \\
\mathrm{DH} \\
\mathrm{ECM}\end{array}$ \\
\hline
\end{tabular}

generations change, mindsets and habits change and so does the need for information. For a long time now the internet and social media have played a key role in everyday life, so the inclusion of webbased tools in drug regulation must undeniably be one of the future approaches. This idea is not new, bearing in mind some mobile applications that have already been developed to control and analyse social media. ${ }^{45}$ The most recent proof of this is the joint EMA-HMA-EC collaboration on the development of electronic product information (ePI). Its aim is the development and implementation of an electronic source of scientifically validated information on medicinal products authorised in the EU. This information will be accessible to both patients and healthcare specialists, 
with one of the expected benefits being facilitation of the decision-making process on treatment. This could be of great value to hospital staff and clinical pharmacists. The ePI is designed to complement the electronic medical dossier as well as the digitalisation of healthcare in Europe in general. ${ }^{6}$ Interestingly, one of the key principles suggests making ePI available through scanning technologies. As we know, the packaging of medicinal products is an important part of their regulatory documentation. Moreover, the outer package of the product is the first part which consumers encounter. The information it holds is immediately obvious and accessible. It seems logical to consider the packaging of medicinal products as a source of safety information and could be suitable for placement of key information about the product or special warnings, as applicable. Visual elements and pictograms are one way to make the best use of the limited space on the outer packaging box. However, contemporary drug regulations somehow fail to make the best use of this.

An analysis of the significance of warning symbols on medicine packs may be difficult as there are a lot of national differences. Information on packaging varies greatly among EU member states. Moreover, some requirements are obligatory in the EU while others are a matter of national regulation. In general, an overview of symbols and warning texts which are present on packaging of medicines in EU countries shows a variety of unsynchronised and nationally specific symbols. Despite some similarities, the warnings remain very different in terms of text and pictograms. It is worth noting, however, that in many countries medicines aimed for hospital use only (preparation and administration) are marked with a special warning (table 1).
An interesting example of a countryexclusive warning is the red letter $\mathrm{K}$ which concerns intravenous medicines containing more than $1 \mathrm{mEq} / \mathrm{mL}$ potassium, which can be lethal if not diluted before use. It is quite obvious that this warning is primarily aimed at hospital staff. Having said that, it is reasonable to ask to what extent the packaging of medicines is key for safety surveillance and how it can be improved in order to be useful for healthcare professionals and patients. In the dynamic decision-making process in hospitals, a quick look or a scan of the medicinal package which will provide the most valuable information on a medicinal product seems like a dream worth aiming for. In the hospital environment where medicines are predominantly not self-administered by patients, it is the hospital pharmacists' knowledge and level of understanding that is key for pharmacotherapy and outcome. Perhaps hospital and clinical pharmacists are already a step ahead in using technologies and product information.

With this in mind, the development of the ePI is a good opportunity to take a closer look at the packaging of medicinal products and focus on its synchronisation across Europe. The introduction of medicine packaging as a risk minimisation measure for various stakeholders would be a milestone in drug regulation, especially if linked to a digital platform containing accurate and scientific information. Maybe this process should start with hospital-only medicinal products.

Funding The authors have not declared a specific grant for this research from any funding agency in the public, commercial or not-for-profit sectors.

Competing interests None declared.

Patient consent for publication Not required.

Provenance and peer review Not commissioned; internally peer reviewed. (c) European Association of Hospital Pharmacists 2021. No commercial re-use. See rights and permissions. Published by BMJ.

A) Check for updates

To cite Getova V, Getov I. Eur J Hosp Pharm Epub ahead of print: [please include Day Month Year]. doi:10.1136/ejhpharm-2021-002960

Eur J Hosp Pharm 2021;0:1-2.

doi:10.1136/ejhpharm-2021-002960

\section{ORCID iDs}

Violeta Getova http://orcid.org/0000-0002-7103-3892

llko Getov http://orcid.org/0000-0001-6513-9327

\section{REFERENCES}

1 González-Pérez Y. Disinformation in the information age. Eur J Hosp Pharm 2020;27:319-21.

2 European Medicines Agency. EMA medical terms simplifier. Plain-language description of medical terms related to medicines use, EMA/158473/2021; 2021. https://www.ema.europa.eu/en/documents/other/emamedical-terms-simplifier_en.pdf

3 Getova V. Regulatory and practical aspects of patients' participation in drug safety surveillance. PhD thesis, 2018. https://ras.nacid.bg/api/reg/FilesStorage?key= 1140ffc3-d180-448f-9f88-98a22557af95\&mimeType= application/pdf\&fileName=Violeta\%20Getova\% 20PhD\%20thesis\%202018.pdf\&dbld=1

4 Brosch S, de Ferran A-M, Newbould V, et al. Establishing a framework for the use of social media in pharmacovigilance in Europe. Drug Saf 2019:42:921-30.

5 van Stekelenborg J, Ellenius J, Maskell S, et al. Recommendations for the use of social media in pharmacovigilance: lessons from IMI WEB-RADR. Drug Saf 2019:42:1393-407.

6 European Medicines Agency, Heads of Medicines Agencies, European Commission. Electronic product information for human medicines in the EU: key principles, EMA/503860/2018, 2018. Available: https:// www.ema.europa.eu/en/documents/regulatoryprocedural-guideline/electronic-product-informationhuman-medicines-european-union-key-principles_en. pdf

7 European Commission. Guideline on the packaging information on medicinal products for human use authorized by the Union, July 2015, revision 14.3, 2015. Available: https://ec.europa.eu/health/sites/ default/files/files/eudralex/vol-2/2015-07_14_3_ packaging.pdf 